\title{
Incidencia de la articulación público- privada en la promoción del sector software de Argentina
}

\section{fncidencia de ta articulación público-privada en ta promoción del sector software de Argentina}

\author{
Carina Borrastero \\ carinaborrastero@eco.unc.edu.ar
}

\begin{abstract}
Doctora en Ciencias Sociales, Universidad Nacional de Córdoba, Facultad de Ciencias Económicas, Centro de Investigaciones en Ciencias Económicas (UNC-CONICET).

Bv. Enrique Barros s/n, Facultad de Ciencias Económicas, primer piso, of. 230, Ciudad Universitaria, Córdoba, Argentina, CP. 5000
\end{abstract}




\title{
Resumen
}

El objetivo del trabajo es analizar la incidencia del vínculo Estado-empresarios en el proceso de surgimiento y configuración de la principal política pública de promoción sectorial de la industria del software en Argentina en las últimas décadas: la denominada "Ley de Software". La perspectiva analítica recoge elementos del enfoque estratégico relacional de Jessop, así como contribuciones de la nueva sociología del desarrollo. Optamos por una metodología cualitativa basada en el análisis bibliográfico y documental, y entrevistas a informantes clave, lo cual permitió la reconstrucción de la génesis de la ley en torno a la instalación de la cuestión y el armado de la política. El análisis del proceso demuestra que la política fue producto de una intensa articulación público-privada con altos grados de enraizamiento y reciprocidad, e incidió positivamente en el crecimiento sectorial durante la década de los 2000 .

Palabras clave: Argentina, articulación público-privada, Ley de Software, promoción sectorial.

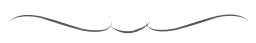

\begin{abstract}
The objective of this work is to analyze the incidence of the State-business relationship in the process of emergence and configuration of the main public sectoral promotion policy for software industry in Argentina in the last decades: the so-called "Software Law". The analytical perspective includes elements of Jessop's strategic relational approach and contributions from the new sociology of development. We opted for a qualitative methodology based on bibliographic and documentary analysis and interviews with key informants, which allowed the historical reconstruction the genesis of the law around the installation of the issue and the setting of the policy. The analysis of the process showed that the policy was the product of an intense public-private articulation with high degrees of embeddedness and reciprocity, and had a positive impact on sectoral growth since the 2000s.
\end{abstract}

Keywords: Argentina, public-private articulation, Software Law, sectoral promotion. 


\section{INTRODUCCIÓN ${ }^{1}$}

En el transcurso de la década de los 2000, la industria argentina de software y servicios informáticos (SSI) comenzó a ocupar un lugar destacado en la estructura productiva del país, en concurrencia con nuevas políticas estatales macroeconómicas y sectoriales cuya canalización y cuyos efectos sobre el sector tuvieron como punto de condensación la entrada en vigencia del primer régimen general de promoción, conocido como "Ley de Software" (Ley nacional N. ${ }^{\circ} 25.922^{2}$ ). El Estado nacional y las entidades representativas del empresariado del sector con más estrecha interacción — la Cámara de Empresas de Software y Servicios Informáticos de Argentina (CESSI) y la Cámara de Informática y Comunicaciones de la República Argentina (CICOMRA) — fueron los actores protagonistas del proceso de emergencia, configuración y consolidación de este régimen que, desde nuestro punto de vista, constituyó el factor precipitante (MacIver, 1949) del salto notorio del desarrollo sectorial local que se observa durante este periodo. La Ley 25.922 se enfoca, sobre todo, en reducir los costos de contratación de mano de obra y los costos de las exportaciones, y opera como un fuerte refuerzo y un punto de condensación de distintas ventajas disponibles en el sector que actuaron de forma conjunta como factores impulsores. Entre estos se encuentran, principalmente, la devaluación del peso argentino (instituida a comienzos de la década), la disponibilidad relativa de mano de obra calificada, la experiencia con que contaban grandes empresas extranjeras de informática instaladas en el país asociadas a la fabricación de hardware, componentes y servicios (como, por ejemplo, IBM, Indra y EDS, entre otras), y el proceso de reestructuración productiva a escala internacional del sector SSI el cual involucraba estrategias de off shoring de la producción hacia localizaciones periféricas con ventajas comparativas y costos relativos convenientes para las compañías globales.

1 Agradecemos de forma sincera las profusas sugerencias de un/a evaluador/a anónimo/a que han contribuido a mejorar sensiblemente este trabajo desde su versión original.

${ }^{2}$ En adelante, así la referiremos (véase el texto completo en http://www.agencia. mincyt.gob.ar/upload/ley_25922-2.pdf . 
La perspectiva de la nueva sociología del desarrollo (NSD) permite considerar las articulaciones público-privadas como factores de incidencia diferencial en el derrotero de los procesos de desarrollo sectorial (Evans, 1995; 1996; Schneider y Wolfson, 1999). Junto con esto, el enfoque estratégico relacional de Jessop (2007, p.1) permite analizar la acción y el poder de las distintas fuerzas sociales en su relación constitutiva con otros órdenes institucionales y otras prácticas sociales, especialmente las capacidades estatales en su vinculación intrínseca con la acción y las capacidades del empresariado como fuerza social relevante en los procesos de desarrollo económico, de modo que contribuyen a comprender la naturaleza relacional de dichas capacidades (Jessop, 2014).

En los últimos años ha crecido de manera sensible en el campo académico y político el interés por el desarrollo sectorial vinculado a la intervención estatal en Argentina (Borrastero, 2011; Castellani 2010, 2006; Castellani y Borrastero, 2013; Castellani y Llanpart, 2012; Castellani y Serrani, 2010; Motta, Morero y Borrastero, 2017; Rougier, 2011; Viguera, 1998). Sin embargo, no identificamos estudios recientes dedicados al análisis de los procesos de construcción de políticas para los sectores de base tecnológica que fueron objeto privilegiado de los planes de desarrollo industrial desde la salida del régimen de convertibilidad cambiaria y estabilización política del país, hasta el fin de ciclo de gobiernos de cuño "peronista" en el $2015^{3}$.

De esta manera, adquiere relevancia la posibilidad de comprender en extensión y profundidad los antecedentes y el proceso de armado (Chibber, 2003) de la política en cuestión (Ozslak y O’Donnell, 1976) para el sector de SSI argentino en el periodo 2000-2015. Esto, al hacer especial énfasis en las circunstancias y decisiones que dieron lugar a los cursos de acción efectivamente adoptados, en suma, a las circunstancias y decisiones que explican por qué los actores involucrados tomaron una ruta y no otra durante los procesos de articulación, y qué consecuencias tuvieron, en una suerte de

${ }^{3}$ Dos importantes estudios de referencia en Argentina en este plano, para otros periodos (década de los ochenta del siglo XX), contextos (retorno democrático y reconstrucción industrial posgobierno de facto aperturista) y sectores (hardware y electrónica) son Aspiazu, Basualdo y Nochteff (1986;1990). 
explicación retrospectiva (Lara Rivero, 2015, en comunicación personal), y al asumir que las coaliciones conformadas entre los agentes estatales y los privados en torno a determinadas políticas deben investigarse y no deducirse de las políticas finalmente adoptadas (Viguera, 1998). Para esto, partimos de la hipótesis según la cual una articulación público-privada con altos grados de enraizamiento y reciprocidad entre la intervención estatal y la acción empresaria a nivel local coadyuvó de manera relevante al crecimiento acelerado del sector de SSI de Argentina desde comienzos de la década del 2000, al operar como factor precipitante en el concierto de los diversos factores impulsores mencionados. Abordaremos este fenómeno con el fin de analizar la incidencia de la relación entre el Estado y los empresarios en el surgimiento y la configuración de la Ley de Software como régimen general de promoción sectorial, en concurrencia con el cual se consolidó de manera paulatina este tipo de producción en el país como un sector de servicios con alto potencial de desarrollo. En función de esto realizamos un estudio de caso sobre el proceso de construcción de esta política y sus resultados generales, lo cual permitió reconocer el rol específico de la articulación públicoprivada local en el devenir de la formulación e implementación del régimen entre el 2000 y el 2015.

El artículo se organiza del siguiente modo. A continuación, en el apartado 2 sistematizamos las herramientas conceptuales del trabajo. En el apartado 3 exponemos los métodos, las fuentes y los resultados del estudio de caso, y en el apartado 4 ponemos en discusión el análisis empírico y presentamos las conclusiones.

\section{HERRAMIENTAS CONCEPTUALES Y METODOLÓGICAS}

\subsection{El enfoque estratégico relacional de Bob Jessop en el análisis del Estado}

Sostenemos que para analizar la acción estatal en términos comprensivos resulta necesaria una concepción relacional de la naturaleza del Estado que habilite interpretar las intervenciones estatales y sus consecuencias tomando en consideración el complejo campo de relaciones sociales que las configuran como tales. Esto es, una concepción del Estado que incorpore las acciones que desarrollan y las condiciones que contribuyen 
a generar otros actores sociales que se vinculan con el Estado e inciden así, de manera sustantiva, en la naturaleza y las características de las intervenciones estatales. De esta manera será posible trascender las visiones Estado-céntricas o mercado-céntricas que caracterizan buena parte de las perspectivas económicas y sociológicas más ortodoxas y, al mismo tiempo, permitirá evitar sustraer al Estado su indudable especificidad y relevancia en la configuración de las relaciones sociales, más allá del tipo de intervenciones específicas que se le atribuyan. En suma, proponemos partir de una comprensión del Estado como un actor cuya forma, apariencia y tipo de intervención varían, no en función de una naturaleza esencial, sino de las actividades que realiza, la escala a la que opera, las fuerzas políticas y sociales que interactúan con él y las circunstancias en las que aquél y estas últimas tienen lugar.

Al tener en cuenta estas consideraciones, el enfoque estratégico relacional (EER) de Jessop sobre el Estado y el poder del Estado se presenta relevante y útil como marco general para los propósitos de este trabajo. Desde dicho enfoque, el aparato y las prácticas del Estado se definen en interdependencia con otros órdenes institucionales y prácticas sociales. Esto significa que, si bien existen límites material y analíticamente remarcables entre el Estado como conjunto institucional y otros órdenes y ámbitos de la vida social, el Estado es un efecto de procesos específicos de organización social que tienden precisamente a producir y reproducir dicha demarcación, y que pueden cambiar con el tiempo (Jessop, 2014, p. 23). Uno de los indicadores más relevantes en este sentido es el esfuerzo realizado por los propios gestores estatales para mantener la integración institucional y la cohesión social dentro de los límites territoriales del Estado, para lo cual estos agentes tienen especialmente en cuenta los códigos, los programas y las actividades de otros sistemas (Jessop, 2014, p. 24). Como afirma Jessop, "se registran intentos continuos de rediseñar la arquitectura institucional del Estado y sus modos de trabajo para así mejorar sus capacidades para alcanzar determinados objetivos políticos" (Jessop, 2014, p. 23).

Esto significa que la coherencia estructural no está garantizada, ni siquiera al interior del propio Estado. Para el autor, aunque las acciones del Estado se concentren en su núcleo, dependen de un amplio espectro de prácticas micropolíticas socialmente diseminadas que limitan la coheren- 
cia en virtud de que ésta depende a la vez de los efectos de determinadas contradicciones y líneas de conflicto (Jessop, 1990).

Con base en esta identidad genérica, afirma Jessop, se conforma un núcleo del aparato estatal que consiste en un conjunto distintivo de instituciones y organizaciones con la función general de definir y garantizar el cumplimiento de las decisiones colectivas de una población dada, en nombre de su interés común (Jessop, 2014, p. 25).

Adicionalmente, a fin de sustentar una concepción del Estado como la que proponemos usar aquí, y comprender de forma más acabada la dinámica de las capacidades de este actor, es necesario asumir también una posición teórica definida en relación con la naturaleza y las características del poder del Estado. En efecto, los conceptos de poder y capacidad suelen estar íntimamente relacionados en la tradición del pensamiento sobre el poder, y en particular sobre el poder del Estado. El enfoque estratégico relacional de Jessop se concentra en el poder como capacidad (más que en la actualización de dicha capacidad). Esto es, concibe el poder como la "capacidad de una determinada fuerza para producir un evento que de lo contrario no ocurriría” (Jessop, 2014, p. 27). Según el autor, "dicha capacidad es inherentemente relacional porque depende de la correspondencia recíproca entre capacidades y vulnerabilidades — las capacidades de la fuerza causal, las vulnerabilidades de aquel sobre el cual tal fuerza opera” (p. 27).

De esta visión sobre el poder estatal rescatamos, en primer lugar, la consideración de las vulnerabilidades del Estado como uno de los elementos que contribuyen a la superación de algunas de las carencias de las teorías del desarrollo. Para Jessop, tanto los recursos y poderes que sustentan su autonomía relativa como sus vulnerabilidades son propios y distintivos del Estado. Dichas vulnerabilidades se asocian, principalmente, al hecho de que las intervenciones estatales dependen de recursos generados en otros ámbitos sociales. Del mismo modo, los poderes o las capacidades estructurales del Estado dependen de diversas capacidades y vulnerabilidades de las fuerzas sociales que desbordan su aparato jurídico-político. Tanto las capacidades como las vulnerabilidades están inscriptas, según Jessop, en las estructuras sociales, pueden perdurar en el tiempo y tornarse recíprocas o asimétricas. Es decir, asumen un carácter relacional. Por tanto, al analizar el poder no 
es suficiente concentrarse en las propiedades de agentes individuales considerados de forma aislada, ni presuponer la imposición unilateral de la voluntad de alguno de los actores en juego, como, por ejemplo, la lógica de acción general (Jessop, 2014, p. 28). El poder relativo y los cambios en las capacidades/vulnerabilidades de cada actor dependen del balance de fuerzas entre ellos. Al mismo tiempo, el autor afirma que mientras más aumenta la intervención estatal, el poder del Estado está más subordinado o vinculado con las fuerzas externas (Jessop, 1990).

No obstante, además de las capacidades/vulnerabilidades estructurales, este enfoque admite como otro de sus elementos fundamentales "una medida de autorreflexión" (Jessop, 2014, p. 30) posible de los agentes acerca de las identidades e intereses que orientan su accionar. De allí el componente estratégico que rescatamos en segundo lugar. Esto implica considerar a los agentes capaces de aprender de su experiencia, adaptarse a contextos específicos y producir transformaciones. De manera que el enfoque admite así también la posibilidad de crear conocimientos y reformular estrategias, siempre en un contexto determinado de oportunidades y limitaciones. Dichas creaciones y reformulaciones se dan, a su vez, en el marco del "horizonte cognitivo de posibilidades de los actores relevantes" (Hyoung Ji y Kytir, 2014). Esto es, los agentes actúan de manera selectiva según sus conocimientos, sus experiencias y su capacidad intelectual, por lo que, al interior del conjunto de acciones potenciales que no se materializan, se encontrarán algunas que nunca se habrán intentado siquiera porque se encuentran más allá de este horizonte. Un cambio en la "selectividad cognitiva" (2014) de los actores, producido, por ejemplo, a través del aprendizaje derivado de la implementación de políticas, puede abrir nuevas posibilidades de acción. De forma complementaria a la dimensión cognitiva del registro de los actores abordada por el EER, es útil considerar la dimensión cultural de la emergencia y la configuración de las intervenciones estatales, en tanto las ideas socialmente construidas tienen efectos performativos sobre la acción —en particular, según Jessop (2009), las ideas económicas_- A partir de esta premisa, el autor propone el concepto de imaginarios económicos como sistemas semióticos que dan sentido y forma al campo económico. Estos identifican, privilegian y buscan estabilizar algunas actividades económicas al interior de la totalidad de las relaciones económicas y transformarlas en objetos de observación, cálculo y gobierno. A nivel meso y macro, los 
imaginarios se desarrollan a medida que las fuerzas económicas, políticas e intelectuales buscan (re)definir subconjuntos específicos de actividades económicas como sujetos, sitios y desafíos de la competencia o como objetos de regulación, y así articular estrategias, proyectos y visiones orientadas a estas economías imaginadas. La "economía basada en el conocimiento", por ejemplo, según Jessop, puede leerse como un orden semiótico distintivo que (re)articula varios géneros, discursos y estilos en torno a una nueva estrategia económica, un proyecto estatal y una visión hegemónica que afecta a diversos órdenes institucionales y al mundo de la vida. Entre las principales fuerzas involucradas en estos esfuerzos el autor destaca a los partidos políticos, los grupos de reflexión, los organismos como la Organización para la Cooperación y el Desarrollo Económicos (OCDE) y el Banco Mundial, los intereses organizados (p. ej., las asociaciones empresariales y los sindicatos), los movimientos sociales y los medios de comunicación (Jessop, 2009).

En tercer lugar, a la par de las posibilidades y las limitaciones estructurales de distinto orden que ya mencionamos, es necesario registrar también las oportunidades coyunturales que dan lugar al conjunto de acciones efectivamente realizadas.

En cuarto lugar, es preciso contemplar las estrategias políticas en el marco de las cuales se desenvuelve la acción de los agentes estatales (2009). Esto es: si bien dicha acción tiene un carácter parcialmente fragmentario o no necesariamente homogéneo, remite siempre a algún tipo de estrategia política concebida al interior de la unidad institucional. Dicha estrategia será por definición selectiva y privilegiará a determinados actores más que a otros (por ejemplo, a los de un sector económico particular), identidades, estrategias del resto de las fuerzas sociales y demás prioridades, al considerar, a su vez, su propio impacto en las estrategias y las capacidades de las fuerzas que entran en una vinculación específica con el Estado en una situación determinada. En una dirección similar, Ozslak y O’Donnell (1976) apuntan a que las políticas estatales no son unidades discretas que pueden estudiarse prescindiendo del contexto en el que se adoptan o inciden.

Por último, la noción de factor precipitante de MacIver resulta de amplia utilidad en el propósito de comprender el rol posible de intervenciones estatales específicas en el concierto del resto de las intervenciones y de 
otros factores contextuales. Se trata de "algún factor o condición específica que consideramos que desvía de la dirección preestablecida de los asuntos y que rompe un equilibrio preexistente, o que deja libres tendencias o fuerzas reprimidas o latentes hasta entonces" (MacIver, 1949, p. 149). El precipitante es un tipo de factor "introducido, o que emerge, de suerte que provoca una serie de repercusiones o reacciones que cambian muy significativamente la situación total" (MacIver, 1968, p. 377). A partir de una noción como tal es posible comprender el modo en que, cuando un determinado sistema o situación operan de forma reproductiva - aun en el marco de un contexto que en potencia habilita el cambio- dicho cambio no ocurre hasta que "algo" interviene, en nuestro caso, la acción emergida de la articulación público-privada. La complejidad de esta visión del Estado en relación con las necesidades analíticas del presente trabajo permite incorporar la acción de los empresarios y la articulación público-privada como variables constituyentes del modelo de estudio del desarrollo sectorial que se propone.

\subsection{La nueva sociología del desarrollo en el análisis de las articulaciones público-privadas}

$\mathrm{Al}$ interior de la nueva sociología del desarrollo (NSD) consideramos que las líneas de investigación específicamente centradas en la relación entre el Estado y los empresarios contribuyen, de manera sustantiva, a comprender en términos socioeconómicos y relacionales la participación de los actores protagónicos de los procesos de desarrollo sectorial.

La intervención estatal (IE) constituye una variable fundamental para comprender los procesos de desarrollo y, en particular, la evolución de una estructura productiva cuya orientación ha sido especialmente configurada por la acción del Estado (como suele ocurrir habitualmente en las economías en desarrollo).

Definimos aquí la IE como el conjunto de acciones del Estado identificables en un marco temporal determinado que dan cuenta de sus funciones regulatorias y productivas. Según su ámbito de incidencia, se tratará de intervenciones económicas o político-institucionales. Las intervenciones económicas (IEE) son las acciones regulatorias del mercado y las acciones 
del Estado como agente económico (esto es, como productor y demandante de bienes y servicios y/o financiador directo o indirecto de la actividad de los agentes privados) (Castellani, 2010). En particular, esta clase de intervenciones definen el tipo y la orientación de las transferencias de recursos públicos hacia el capital (Castellani, 2006). Por su parte, las intervenciones político-institucionales (IPI) son las acciones del Estado destinadas a crear y/o modificar arreglos institucionales específicos para la definición e implementación de políticas públicas. A partir de estas categorías es posible abordar tanto las IE dirigidas a establecer las formas de asignación de los recursos económicos como las orientadas a instituir transformaciones en los mecanismos de toma de decisiones (Borrastero, 2011). En este sentido, asumimos que dichas intervenciones afectan directa e indirectamente la actividad económica y la acción política de los agentes privados. Los roles que el Estado puede asumir en relación con el desarrollo comprenden distintos grados de intervención y objetivos determinados.

La calidad de la IE constituye una dimensión analítica fundamental de los procesos de desarrollo. La experiencia histórica del siglo XX muestra que no es suficiente con realizar intervenciones, sino que estas deben ser autónomas y eficientes para generar procesos de desarrollo sostenidos, y cómo esto da cuenta de su calidad ${ }^{4}$. De esta manera, de acuerdo con los autores de la NSD, la calidad de la intervención estatal se define en dos dimensiones: una dimensión interna relativa a las capacidades del aparato estatal para realizar las intervenciones, y una dimensión externa que remite a las relaciones del Estado con el entorno socioeconómico (tanto a la capacidad estatal para inducir cambios en la conducta de los actores sociales o evitar bloqueos a las intervenciones como a la capacidad de articular intereses con los actores y garantizar su adecuada implementación).

- La dimensión interna implica: a) el desarrollo de las capacidades administrativas (coherencia y cohesión de las agencias estatales involucradas); b) los recursos financieros, organizacionales y técnicos con los que cuenta el Estado para realizar las intervenciones; c) la racionalidad estratégica (orientada a una finalidad común) que el

\footnotetext{
${ }^{4} \mathrm{~A}$ fin de desarrollar las nociones relativas a la calidad de la IE nos basamos en el trabajo exhaustivo de Castellani y Llanpart (2012).
} 
Estado necesita desplegar para incidir en el desarrollo de ámbitos de actividad específicos.

- La dimensión externa involucra: a) el grado de autonomía del aparato estatal para la toma de decisiones estratégicas que inevitablemente entrañan beneficios para determinados sectores económicos y sociales, y perjuicios para otros; b) el nivel de enraizamiento en la estructura social/productiva que permite la connivencia necesaria con los actores protagonistas de los sectores económicos en cuestión; c) el grado de reciprocidad alcanzado en el cumplimiento de los objetivos y condiciones surgidas del tipo de articulación públicoprivada generada, lo que involucra también la capacidad de disciplinamiento de los actores económicos por parte del Estado en pos de la consecución de los objetivos del desarrollo (Amsden, 1992) .

Hasta aquí enfocamos la mirada en el polo del Estado para proponer herramientas de análisis de los vínculos Estado-empresarios en los procesos de desarrollo sectorial. Nos concentraremos ahora en el otro polo de la relación, en particular en los patrones organizativos que los sectores empresariales establecen para interactuar con el aparato estatal, el tipo de acciones que realizan y su incidencia en la conformación y orientación del aparato estatal (Castellani y Llanpart, 2012, p. 174) .

Emplearemos el concepto de acción empresaria para referirnos a un tipo particular de acción social, por la cual un conjunto de actores capitalistas se organizan en torno a objetivos determinados y desarrollan diversas prácticas de articulación con el Estado u otros actores sociales a fin de conseguirlos (Castellani y Llanpart, 2012, p. 17). Dicha acción involucra también dos dimensiones: una económica y otra política. La primera remite al conjunto de prácticas y decisiones microeconómicas de los empresarios (como el nivel de producción e inversión, la política de contrataciones, la fijación de precios y otras) decisivas para el funcionamiento del modelo de acumulación. La dimensión política de la acción empresaria" se define en función de

${ }^{5}$ En relación con la cuestión de la autonomía estatal, tomamos aquí como herramienta de análisis las contribuciones de Evans (1995) sobre la autonomía enraizada.

${ }^{6}$ Para una revisión exhaustiva de las líneas de investigación sobre estas problemáticas véase Beltrán (2012). 
las prácticas orientadas a articular intereses y políticas con el sector público y otros actores sociales. En este plano, son acciones empresarias tanto la instalación de demandas hacia el Estado como las estrategias de participación o influencia en la formulación o implementación de políticas públicas.

La acción empresaria, a su vez, puede ser de tipo corporativo o individual. En términos generales, la acción colectiva producida por este tipo de actores se canaliza a través de sus organizaciones representativas (Dossi y Lissin, 2010).

Tirado (2006) explica de forma estilizada que los capitalistas pueden recurrir a cuatro vías principales para acceder al Estado y satisfacer sus demandas: a) acudir de forma directa al gobierno o al parlamento para plantearlas; b) vincularse con partidos políticos con el fin de lograr que defiendan sus intereses o al menos no interfieran con ellos; c) actuar dentro de sus propias organizaciones representativas con el propósito de generalizar sus intereses y concretarlos desde allí; y d) comparecer directamente ante la opinión pública para incidir sobre ella en la defensa de sus intereses y demandas.

Si bien hablamos en términos generales de una acción coordinada en función de intereses determinados, es necesario considerar — con Beltrán (2012) — que los procesos de agregación de intereses no son automáticos, sino que la heterogeneidad del empresariado hace que la definición de los objetivos políticos emerja del acuerdo entre partes con intereses a menudo divergentes. De esta manera, las acciones políticas muchas veces dan cuenta de posiciones que resultan del debate político y el cálculo estratégico, y no de la posición de los empresarios.

En esta misma dirección, Evans (1995) postula que tampoco las capacidades del empresariado para desplegar estrategias planificadas y concretar objetivos deben considerarse elementos dados. Por el contrario, son maleables y pueden constituir un producto de los roles asumidos por el Estado en la orientación de la economía. Por su parte, Schneider y Wolfson (1999) recuerdan que la acción colectiva de las empresas y asociaciones empresarias normalmente depende de acciones previas del Estado que promovieron o desalentaron diversas formas de organización. Esto, a contramano de las perspectivas neoliberales que entienden el poder del empresariado como independiente de la acción estatal. 
Ahora bien, es preciso recordar que los empresarios detentan innegablemente una posición privilegiada en la estructura social respecto a los demás grupos o clases. Si bien esta posición no es equivalente a una determinación estructural sobre las acciones del Estado, las decisiones y los comportamientos empresarios inciden con fuerza sobre el grado de estabilidad o inestabilidad de las variables macroeconómicas que el Estado debe manejar (Viguera, 1998). Esto otorga a este grupo social un poder estructural diferenciado, en ocasiones esencialmente negativo cuando consiste más en la capacidad de veto sobre las decisiones estatales que en la influencia positiva en la definición de las políticas públicas. Al tener esto en cuenta puede afirmarse que el Estado y el sector privado están obligados a ajustar mutuamente sus intereses y objetivos, con resultados variables según sus recursos relativos (Heredia, 1996). De esta manera, si las influencias son mutuas, es preciso analizar qué tipos de articulaciones público-privadas pueden establecerse entre ellos. Dichas articulaciones presentan diversos grados de institucionalización, legalidad y visibilidad. Según Castellani (2006, p. 16) pueden reconocerse las siguientes:

- Las prácticas institucionalizadas de articulación son aquellas demandas que los empresarios dirigen al Estado, directa, formal y públicamente, a través de sus entidades corporativas y vías oficiales de comunicación (publicaciones periódicas de las corporaciones, discursos en convenciones, congresos y demás eventos públicos, y medios de comunicación social).

- Al tomar en consideración elementos aportados por Schneider (1995) es posible identificar también la colaboración como un subtipo de práctica institucionalizada de articulación. Se trata de la situación en la cual burócratas y actores industriales comparten información y recibien estos últimos subsidios a cambio de incrementos en su desempeño. La colaboración involucra confianza entre los actores para el logro de las metas comunes que deben ser positivas para que exista colaboración en estos términos ${ }^{7}$. Así como existen condiciones favorables a la colaboración tales como la confianza, la probidad y la

\footnotetext{
${ }^{7}$ Schneider aclara que trabajar juntos con una intención fraudulenta es colusión
} (1995). 
iniciativa, existen otras que la desincentivan u obstaculizan, entre las cuales Schneider destaca una fuerte concentración del mercado.

- Las prácticas de influencia directa sobre el Estado (lobby) son mecanismos de articulación informales que ejercen los empresarios, los directivos o las corporaciones que tienden a mantener fuera del dominio público. En términos generales, si salen a la luz sucede a partir de denuncias periodísticas o políticas.

- Las prácticas de colonización de espacios de la administración pública involucran la colocación en puestos decisorios de personas comprometidas en la defensa de los intereses empresariales. Pueden ser más o menos abiertas a la opinión pública, pero captarlas es metodológicamente posible al investigar el origen social y la trayectoria profesional de los funcionarios.

- Las prácticas colusorias son aquellas por las cuales se establecen acuerdos entre los empresarios y el aparato estatal (o algún reducto de este) a fin de garantizar a las empresas condiciones de operación de bajo riesgo, lo cual les permitan obtener beneficios monopolísticos. Normalmente, se caracterizan por su opacidad, si bien pueden identificadarse a partir de fuentes de informaciones periodísticas o políticas, o directamente a través de testimonios de los involucrados u otros actores interesados en su difusión.

- Por último, se encuentran mecanismos de articulación ilegales, esto es, prácticas de corrupción que consisten en sobornos de los empresarios a los funcionarios que garantizan intervenciones estatales favorables a los intereses de los primeros. Como es evidente, dichas prácticas son secretas $\mathrm{y}$, por tanto, difíciles de investigar y demostrar, pero pueden ser, eventualmente, accesibles a través de denuncias periodísticas, políticas o judiciales.

Huelga aclarar que las distinciones analíticas establecidas entre los distintos mecanismos de articulación público-privada, en la práctica, suelen ocurrir de manera conjunta y en diversas combinaciones. Cabe, al mismo tiempo, destacar que el grado de visibilidad de las diversas prácticas favorecerá o complejizará su captación, y de esto dependerán las alternativas metodológicas disponibles para investigarlas. 


\subsection{El armado de las políticas en cuestión}

A partir del marco analítico general que presentamos hasta aquí es posible recoger algunas herramientas conceptuales más específicas que permiten relevar el proceso de construcción y configuración de una política estatal como la que nos ocupa.

Así, Ozslak y O’Donnell conciben la política estatal como,

un conjunto de acciones y omisiones que manifiestan una determinada modalidad de intervención del Estado en relación con una cuestión que concita la atención, interés o movilización de otros actores en la sociedad civil. De dicha intervención puede inferirse una cierta direccionalidad, una determinada orientación normativa, que previsiblemente afectará el futuro curso del proceso social hasta entonces desarrollado en torno a la cuestión. (1976, p. 565)

Dichas acciones y omisiones ocurren en un momento histórico y un contexto determinados que dan cuenta de la posición "predominante" del Estado frente a la cuestión suscitada. La cuestión es, entonces, un asunto socialmente problematizado, no cualquier demanda o necesidad de los integrantes de una sociedad, sino aquellas que determinados grupos sociales o individuos estratégicamente situados consideran que es preciso atender y están en condiciones de promover su incorporación a la agenda pública.

Metodológicamente, Ozslak y O’Donnell propone encarar los estudios empíricos de políticas estatales al analizar el periodo previo al surgimiento de la cuestión, al observar,

quién la reconoció como problemática, cómo se difundió esa visión, quién y sobre la base de qué recursos y estrategias logró convertirla en cuestión. El examen de este "período de iniciación" puede enriquecer nuestro conocimiento sobre el poder relativo de diversos actores, sus percepciones e ideología, la naturaleza de sus recursos, su capacidad de movilización, sus alianzas y conflictos y sus estrategias de acción política. Resumiendo, ¿quién y cómo problematiza un asunto? ¿Quién, cómo y cuándo logra convertirlo en cuestión? ¿Sobre la base de qué recursos y alianzas?, ¿con qué oposición? ¿Cuál es la definición inicial de la cuestión? (1976, p. 564) 
Por su parte, Chibber (2003) ofrece una propuesta de abordaje complementaria y pertinente para nosotros en el propósito de seguir el derrotero de la política en cuestión, que consiste en el seguimiento del armado de la política. Mediante este procedimiento es posible conocer las relaciones que se establecen en situaciones determinadas entre las presiones de los grupos sociales y los cambios efectivos en las políticas públicas, y el modo en que se entretejen las acciones de los distintos actores para dar lugar a esas configuraciones situadas espacial y temporalmente.

Viguera (1998) sostiene una postura similar al puntualizar que las coaliciones conformadas entre los agentes estatales y los privados en torno a determinadas políticas deben investigarse y no deducirse de las políticas finalmente adoptadas. En este sentido, el autor recuerda que el hecho de que existan beneficiarios de ciertas políticas no significa que estos hayan participado en su diseño o implementación, ni siquiera al impulsar su formulación inicial. Por otra parte, los intereses de los actores sociales no son estáticos, por lo que aun en los casos en que efectivamente se articulan con el Estado y participan en la definición de las políticas públicas, estos procesos adoptan formas diversas y, en muchos aspectos, circunstanciales.

\subsection{Métodos y fuentes}

Para el abordaje del problema de estudio desarrollamos una estrategia metodológica cualitativa a través del estudio del caso (Denzin y Lincoln, 2005), basada en las técnicas de análisis bibliográfico, análisis documental y entrevistas semiestructuradas a informantes clave.

Nuestras principales fuentes de información consistieron en estudios disponibles sobre el sector, documentos oficiales del Estado, documentos institucionales de las entidades empresarias, sitios web de las empresas, prensa, funcionarios y exfuncionarios del gobierno provincial, directivos o empleados jerárquicos de las entidades empresarias, directivos o empleados jerárquicos de las empresas y referentes del campo académico vinculados al sector local.

El relevamiento cualitativo lo guió el siguiente esquema de variables que presentamos de forma desagregada en la Tabla 1 y acompañamos con la 


\section{información relativa a las técnicas de análisis y las fuentes empleadas de manera específica para cada una.}

Tabla 1. Esquema de variables del estudio de caso

\begin{tabular}{|c|c|c|c|c|c|}
\hline $\begin{array}{l}\text { Variables } \\
\text { complejas }\end{array}$ & Dimensiones & Categorías & Indicadores & $\begin{array}{c}\text { Técnicas de } \\
\text { análisis }\end{array}$ & Fuentes \\
\hline \multirow{6}{*}{$\begin{array}{l}\text { Intervención } \\
\text { estatal }\end{array}$} & \multirow[b]{2}{*}{$\begin{array}{l}\text { Intervenciones } \\
\text { económicas. }\end{array}$} & \multirow[b]{2}{*}{$\begin{array}{l}\text { Estratégicas - } \\
\text { no estratégicas. }\end{array}$} & $\begin{array}{l}\text { Contenido y destinatarios de } \\
\text { las medidas. }\end{array}$ & \multirow{6}{*}{$\begin{array}{l}\text { Análisis } \\
\text { bibliográfico } \\
\text { y } \\
\text { documental, } \\
\text { entrevistas. }\end{array}$} & \multirow{6}{*}{$\begin{array}{l}\text { Bibliografía, } \\
\text { documentos } \\
\text { oficiales, } \\
\text { prensa, } \\
\text { informantes } \\
\text { clave. }\end{array}$} \\
\hline & & & $\begin{array}{l}\text { Destino y envergadura de } \\
\text { las principales transferencias } \\
\text { directas e indirectas de } \\
\text { recursos públicos. }\end{array}$ & & \\
\hline & \multirow{4}{*}{$\begin{array}{l}\text { Intervenciones } \\
\text { político- } \\
\text { institucionales. }\end{array}$} & \multirow{4}{*}{$\begin{array}{l}\text { Estratégicas- } \\
\text { no estratégicas. }\end{array}$} & $\begin{array}{l}\text { Contenido y destinatarios de } \\
\text { las medidas. }\end{array}$ & & \\
\hline & & & $\begin{array}{l}\text { Nuevos arreglos } \\
\text { institucionales creados. }\end{array}$ & & \\
\hline & & & $\begin{array}{l}\text { Trayectoria de los arreglos } \\
\text { institucionales específicos } \\
\text { (cambios observados durante } \\
\text { el periodo y proyección en el } \\
\text { tiempo). }\end{array}$ & & \\
\hline & & & $\begin{array}{l}\text { Vínculos con el sector privado } \\
\text { y otros ámbitos del sector } \\
\text { público (universidades). }\end{array}$ & & \\
\hline \multirow{3}{*}{$\begin{array}{l}\text { Acción } \\
\text { empresaria }\end{array}$} & \multirow{3}{*}{$\begin{array}{l}\text { Acciones } \\
\text { político- } \\
\text { institucionales. }\end{array}$} & \multirow{3}{*}{$\begin{array}{l}\text { Estratégicas- } \\
\text { no estratégicas. }\end{array}$} & Asociación institucional. & \multirow{3}{*}{$\begin{array}{l}\text { Análisis } \\
\text { bibliográfico } \\
\text { y } \\
\text { documental, } \\
\text { entrevistas. }\end{array}$} & \multirow{3}{*}{$\begin{array}{l}\text { Bibliografía, } \\
\text { documentos } \\
\text { institucionales, } \\
\text { prensa, } \\
\text { informantes } \\
\text { clave. }\end{array}$} \\
\hline & & & Acciones de autopromoción. & & \\
\hline & & & Vínculos con el sector público. & & \\
\hline $\begin{array}{l}\text { Desempeño } \\
\text { sectorial }\end{array}$ & $\begin{array}{l}\text { Desempeño } \\
\text { económico de } \\
\text { las empresas. }\end{array}$ & $\begin{array}{l}\text { Alto- } \\
\text { medio-bajo. }\end{array}$ & $\begin{array}{l}\text { Evolución de los indicadores } \\
\text { económicos sectoriales: } \\
\text { empleo, cantidad de empresas, } \\
\text { facturación y exportaciones. }\end{array}$ & $\begin{array}{l}\text { Análisis } \\
\text { bibliográfico } \\
\text { y } \\
\text { documental. }\end{array}$ & $\begin{array}{l}\text { Bibliografía, } \\
\text { documentos } \\
\text { oficiales, } \\
\text { prensa. }\end{array}$ \\
\hline
\end{tabular}

Fuente: elaboración propia. 
Cabe aclarar aquí que durante el periodo analizado (2000-2015) se implementó una variedad de políticas estatales con incidencia esperable sobre el sector de SSI (principalmente, macroeconómicas); en segunda medida, vinculadas al sector pero de tipo transversal, como, por ejemplo, las orientadas a la formación masiva de recursos humanos (programas de becas y entrenamiento, programas de sensibilización y motivación a la innovación y el emprendedurismo); y, por último, intervenciones estatales vinculadas a sectores, innovación o formación tecnológica que, de forma indirecta, pueden promover una mayor integración industrial del SSI a partir de la orientación de la demanda del Estado (plan "Conectar igualdad”, desarrollo del sistema público de Televisión Digital Abierta, construcción de satélites, y plan "Argentina Innovadora 2020", entre otras). No obstante, y como ya señalamos en la "Introducción", este trabajo toma como unidad de análisis la Ley de Software en cuanto política sectorial y destinada a las pymes ${ }^{8}$ que, si bien se enfoca en mejorar las condiciones de la oferta y, en ese sentido, es parcial y relativamente excluyente, condensó y encausó en su momento las demandas históricas del sector de SSI desde las décadas anteriores, de modo que operaba como canal del derrotero sectorial en el marco de los impulsos provenientes del contexto y en virtud de la dinámica de instalación y canalización de la cuestión por parte de los actores en posición predominante para ello?.

Por último, cabe asumir las limitaciones tanto del alcance del análisis como de las posibilidades de generalización de los resultados empíricos obtenidos, propias de todo estudio de caso.

${ }^{8}$ Acerca de las políticas de incentivo a la radicación de centros de desarrollo de software de empresas transnacionales en el país — la mayoría instaladas en Córdoba (Motorola, Intel, EDS e Indra, principalmente) — hemos trabajado profusamente en otros textos (véase, p. ej., Borrastero y Castellani, 2018).

${ }^{9}$ En este sentido, podría decirse, por ejemplo, que las políticas de formación de recursos humanos (RRHH) o las de promoción de la demanda tuvieron un potencial de tracción significativo, pero ya en instancias posteriores al crecimiento propio del sector, en términos de creación de empresas y empleo que el régimen habilitó. Incluso, las políticas de RRHH podrían leerse como respuesta a las rigideces surgidas del propio crecimiento demográfico del sector posterior a la devaluación monetaria y la implementación del régimen. 


\section{RESULTADOS DEL ESTUDIO DEL CASO}

Desde fines de la década de los noventa, las organizaciones representativas del sector de SSI, con el protagonismo de la CESSI y CICOMRA, expresaban una serie de demandas vinculadas a la necesidad de apoyo público a esta industria, sobre todo relacionadas con la mejora de las condiciones de inversión, la reducción de los costos laborales y el fomento de las exportaciones.

En virtud de la instauración del régimen de convertibilidad cambiaria, la economía argentina sufrió un proceso de desindustrialización aguda y generalizada que se extendió durante toda la década de los noventa. De esta manera, al fines del 2001 el país se encontraba sumido en una de las crisis socioeconómicas más importantes de su historia, uno de cuyos indicadores principales era el nivel de desempleo que había crecido de forma ininterrumpida desde un 13,8\% a fines de 1999 hasta el 18,3\% a fines del 2001, y llegó así a su pico máximo a comienzos del 2002 con un $21,5 \%$ de la PEA. ${ }^{10}$ A partir del estallido social que experimentó el país como producto de esta crisis, se sucedieron políticas monetarias y fiscales federales de diverso tipo cuyo corolario fue la devaluación del peso argentino en el 2002 durante el breve gobierno de Eduardo Duhalde.

A la par de las entidades empresarias sectoriales, desde el ámbito académico se observaba también una ventana de oportunidad para el crecimiento del sector en aquellos años, y esto se reflejaba en distintas investigaciones sobre su nivel de desarrollo y sus potencialidades ${ }^{11}$. Según la visión de estos actores, las características de un mercado doméstico deprimido y las limitaciones para exportar propias del régimen de convertibilidad condicionaron al sector a un crecimiento restringido que podría revertirse o mejorar mediante instrumentos de apoyo estatal específicos.

${ }^{10}$ Datos de la "Encuesta Permanente de Hogares" (INDEC), disponibles en www. indec.mecon.ar.

${ }^{11}$ Estudios que dieron lugar a trabajos publicados en años posteriores como, por ejemplo, los de Bekerman y Guido (2001), Chudnovsky, López y Melitsko (2001), o López (2002), ya circulaban en aquella época. 
En este contexto, a fines del 2000 se desarrolló una serie de reuniones entre la CESSI, CICOMRA y funcionarios del Ministerio de Economía de la Nación, con el objetivo de generar mejores condiciones para invertir en el sector y reducir los costos salariales. A partir de estos encuentros, el Estado nacional anunció una reducción en los aportes patronales de las empresas del sector informático a un valor del 9,2\% que regiría desde el 1 de enero del 2001, medida apoyada por las mencionadas cámaras. Sin embargo, la aguda recesión del periodo que impactaba en las cuentas del Estado, junto con cambios en la gestión del Ministerio de Economía, impidieron que la medida llegara a ponerse en práctica (Gutman, López y Ubfal, 2006).

A fines del 2000 la multinacional tecnológica Motorola anunció su intención de radicar un Centro de Desarrollo de Software (CDS) en Argentina, cuya concreción dependería de los beneficios que ofrecieran las ciudades interesadas en materia impositiva y disponibilidad de recursos humanos calificados. Según Álvaro Ruiz de Mendarozqueta, primer CEO de Motorola en Córdoba, la decisión de instalarse en Argentina formó parte de la estrategia del Global Software Group de la empresa (con CDS en India, Singapur, China, Rusia, Polonia, Italia, Escocia, Canadá, EE. UU., México y Australia), y, por política de costos de la compañía, las radicaciones no debían ser en capitales sino en ciudades de mediana envergadura con disponibilidad de recursos estratégicos (humanos, de infraestructura y naturales). En cualquier caso, no fue a nivel nacional, sino casi exclusivamente local, que se dirimió el caso, y a partir de intensas negociaciones con el Gobierno de la Provincia de Córdoba, la Municipalidad de la capital provincial y las autoridades de la Universidad Nacional de Córdoba, a mediados de 2001 la empresa inauguró su CDS en el centro de Córdoba, donde comenzó a operar con unos veinte ingenieros contratados bajo un programa de subsidios provinciales. En virtud de este acontecimiento, el sector de software argentino adoptó una nueva forma que incluía ahora la presencia específicamente orientada a la producción de software de una gran transnacional tecnológica, lo cual, a partir de mediados de la década, incentivó a su vez la radicación de centros de desarrollo de software de otras transnacionales (algunas ya presentes en el país a partir de otras actividades, como EDS ,HP e Indra) y algunas nuevas (Intel en el 2006, o Gameloft en el 2007). 
Durante el mismo 2001 se fundó la Cámara de Industrias Informáticas, Electrónicas y de Comunicaciones del Centro de Argentina (CIIECCA) como una nueva entidad representativa de un empresariado que pretendía adquirir mayor volumen y relevancia. Además, en la provincia de Córdoba, en relación también con la instalación de Motorola en la ciudad capital, se fundaron el clúster Córdoba Technology (entidad empresaria que agrupaba a las firmas de software locales) y el Instituto Tecnológico Córdoba (entidad civil que agrupaba a las seis universidades del territorio provincial en proyectos vinculados a la formación de recursos humanos para el sector $)^{12}$.

En este marco, la CESSI reimpulsó las demandas sectoriales históricas, inicialmente a través de distintos medios de comunicación. La demanda principal del momento tenía que ver con las elevadas contribuciones impositivas exigidas a las empresas, en el contexto de retracción económica general e industrial en particular ${ }^{13}$. De esta manera, las firmas del sector comenzaron a plantear gradualmente con mayor intensidad la necesidad de políticas públicas que permitieran aprovechar la coyuntura macroeconómica favorable a la exportación, y apuntaban centralmente a la creación de empleo. En segundo lugar, la CESSI demandaba la creación de un comité mixto de políticas públicas que centralizara la acción de las distintas unidades del Estado con injerencia en el sector ( $L a$ Nación, 17 de julio de 2003). Una experiencia por el estilo resultaría superadora con respecto al estilo de políticas y metodologías implementadas en la década de los ochenta, como parámetro histórico inmediatamente anterior en esta materia (Aspiazu, Basualdo y Nochteff, 1990).

De esta manera, la Cámara de Diputados de la Nación comenzó a trabajar en proyectos de ley relacionados con el sector de SSI. Uno de los más rele-

${ }^{12}$ Si bien se trata de instituciones locales que a su vez no son cámaras empresarias, estos dos acontecimientos revisten importancia para dar cuenta del contexto general del país en términos de densificación y organización sectorial en aquellos años.

${ }^{13}$ Véase, por ejemplo, los siguientes artículos de prensa: "Se mudan a Uruguay por falta de incentivos" (La Nación, 20 de junio del 2002); y "Los polos tecnológicos buscan exportar" (La Nación, 20 de junio del 2002); "El software espera la ley de promoción" ( La Nación, 10 de julio de 2003); "Media sanción al proyecto de promoción de la industria del software" (La Nación, 3 de diciembre de 2003). 
vantes era la creación de una ley que declarara como actividad industrial la producción de software.

Para el 2003, bajo el gobierno de Néstor Kirchner, se puso en marcha una batería de políticas económicas y tecnológicas que recogieron las demandas sectoriales, de modo que se profundizaron las condiciones favorables al crecimiento del sector. Las políticas específicas más relevantes adoptadas por el Estado nacional durante el periodo que aquí analizamos fueron las siguientes:

- En el 2003, el Poder Ejecutivo nacional firmó un decreto por el cual la producción de software pasaba a considerarse actividad industrial, pasible por tanto de incorporarse al régimen de promoción vigen$\mathrm{te}^{14}$.

- Durante el mismo año, se creó en el ámbito de las secretarías de Industria, Comercio y de la Pequeña y Mediana Empresa del Ministerio de Economía y Producción de la Nación, el "Programa de Foros Nacionales de Competitividad Industrial de las Cadenas Productivas" ${ }^{15}$. Este programa incluyó a la industria de SSI como una de las nueve cadenas productivas estratégicas para el desarrollo de la economía nacional, a partir de lo cual se constituyó el Foro de Software y Servicios Informáticos. En este foro ${ }^{16}$ participaron funcionarios públicos, representantes de las entidades del sector, empresarios y académicos. Entre los participantes se contaron funcionarios de ministerios nacionales, del Instituto Nacional de Tecnología Industrial (INTI) ${ }^{17}$, el Consejo Nacional de Investigaciones

${ }^{14}$ Véase al respecto el Decreto Ley 25856, disponible en http://www.infoleg.gob. $\operatorname{ar} /$.

${ }^{15}$ En este sentido, véase la Resolución N. ${ }^{\circ}$ 218/2005, disponible en http://infoleg. mecon.gov.ar/infolegInternet/anexos/105000-109999/109722/norma.htm.

${ }^{16}$ Para la descripción, en este apartado, de las acciones desarrolladas en el marco del foro, nos basamos en Gajst (2011).

${ }^{17}$ El Instituto Nacional de Tecnología Industrial se creó en 1957 como organismo autárquico dependiente la Secretaría de Industria, Comercio y de la Pequeña y Mediana Empresa, y desde el 2009 pertenece al Ministerio de Industria de la Nación, constituido en ese año. 
Científicas y Técnicas CONICET ${ }^{18}$, los gobiernos provinciales y municipales, la Cámara de la Industria Argentina de Software (CESSI), la Cámara de Informática y Comunicaciones de la República Argentina (CICOMRA), la Cámara Argentina de Internet (CABASE) ${ }^{19}$, la Cámara Argentina de Industrias Electrónicas, Electromecánicas y Luminotécnicas (CADIEEL) ${ }^{20}$, la Asociación Argentina de Dirigentes de Sistemas (AADS) ${ }^{21}$, la Asociación de Desarrolladores de Videojuegos Argentina (ADVA) ${ }^{22}$, la Unión Industrial Argentina (UIA) ${ }^{23}$ y la Confederación Argentina de la Mediana Empresa (CAME) ${ }^{24}$, representantes de universidades, de polos y clústeres de distintas regiones del país, bancos y organizaciones no gubernamentales como, por ejemplo, la Sociedad Argentina de Informática e Investigación Operativa (SADIO) ${ }^{25}$, el Centro de Investigaciones para la Transformación (CENIT) ${ }^{26}$, la Fundación Vía libre, la Fundación Exportar y Links, y más. De manera simultánea se pusieron en marcha foros regionales —en Córdoba, Rosario, Neuquén, Bahía Blanca, Tandil y Jujuy - que también convocaron a actores del sector privado, la academia y a representantes de los gobiernos provinciales y municipales. En total, asistieron alrededor de 280 personas durante nueve meses a grupos temáticos y foros regionales. De acuerdo con datos de Gutman, López y Ubfal (2006), la mayor parte de los participantes del foro eran representantes de empresas privadas (40\%) o cámaras empresarias (20\%). Alrededor del 20\% de los participantes eran representantes del sector público nacional o provincial, y $15 \%$ provenían de universidades y del sector académico. No asistieron representantes del campo sindical ni trabajadores del sector

${ }^{18}$ El Consejo Nacional de Investigaciones Científicas y Técnicas, instituido en 1958 como organismo autárquico bajo dependencia de la Presidencia de la Nación, y desde el 2007 perteneciente al Ministerio de Ciencia, Tecnología e Innovación Productiva, creado en ese año.

${ }^{19}$ Véase http://www.cabase.org.ar/wordpress/.

${ }^{20}$ Véase http://www.cadieel.org.ar/esp/index.php.

${ }^{21}$ Véase Asociación Argentina de Dirigentes de Sistemas https://www.facebook. com/aads.arg.

${ }^{22}$ Véase http://adva.com.ar/.

${ }^{23}$ Véase http://www.uia.org.ar/.

${ }^{24}$ Véase http://www.redcame.org.ar/.

${ }^{25}$ Véase http://www.sadio.org.ar/).

${ }^{26}$ Véase http://www.fund-cenit.org.ar/home/. 
en cuestión ${ }^{27}$. Si bien el proceso de construcción del espacio del foro involucró a una amplia variedad de actores, los interlocutores principales y directos del Estado nacional continuaron siendo la CESSI y CICOMRA, como ya puntualizamos. Como producto de los debates en el foro se elaboró un plan estratégico sectorial a diez años con la visión de constituir a la Argentina, en cuanto país no central, en un actor relevante del mercado mundial de SSI hacia mediados de la década del 2010. Para esto se definieron diversas estrategias que comprendían: el impulso a las exportaciones, la ampliación del mercado interno, el desarrollo de los recursos humanos necesarios, de la calidad, de la asociatividad, del marco jurídico y del financiamiento, a partir de una fuerte intervención estatal en estos campos y de la articulación público-privada.

- En el año, como resultado de este intenso proceso de construcción institucional por parte de los actores del sector, se sancionó la Ley Nacional de Promoción de la Industria del Software, a partir de un proyecto del Poder Ejecutivo nacional ${ }^{28}$. La cuestión que pretendía resolver el nuevo régimen de promoción era la necesidad de estimular el desarrollo de un sector productivo estratégico para la economía argentina en tanto industria de alto valor agregado con capacidad para generar externalidades positivas para el resto de la economía, generar divisas por aumento del comercio internacional y brindar importantes oportunidades para la incorporación de países en desarrollo a la economía internacional. El Decreto N. ${ }^{\circ} 1594 / 2004$ reglamentó la mencionada ley. Allí se amplía el alcance del régimen de promoción al considerar - junto con la actividad de desarrollo de software - la provisión de distintos tipos de servicios informáticos con valor agregado. A su vez, el decreto explicita que las políticas que involucra la Ley de Software surgen de los lineamientos generales del "Plan Estratégico de Software y Servicios Informáticos 2004-2014", elaborado en el marco del Foro de Competitividad. De

${ }^{27}$ Gutman, López y Ubfal (2006) muestran que solo en dos de los nueve foros (industrias culturales y madera y muebles) participaron representantes del sector sindical, con una participación menor al $10 \%$.

${ }^{28}$ Según Gutman, López y Ubfal (2006), se trató de un ejercicio de coordinación casi sin antecedentes en el diseño de políticas públicas en Argentina, a partir de un enfoque de cadenas de valor que, en su momento, suponía una superación de las tradicionales aproximaciones sectoriales en el diseño de políticas productivas. 
este modo, se fortalecieron de manera gradual distintas políticas de refuerzo de la Ley de Software, orientadas, sobre todo, al financiamiento de las pymes. Los instrumentos principales del régimen de promoción contemplado por la ley continúan vigentes al momento de elaboración de este trabajo y pueden sintetizarse en el siguiente listado, si bien es preciso señalar dos modificatorias legales relevantes posteriores a su sanción original ${ }^{29}$ :

- Estabilidad fiscal por diez años para todos los tributos nacionales que las empresas del sector deban abonar.

- La posibilidad de convertir en bono fiscal el 70\% de las contribuciones patronales en los casos de empresas que realicen al menos una de las siguientes actividades durante el primer año de incorporación al régimen, y dos de ellas desde el segundo año: $\mathrm{I}+\mathrm{D}$, certificación de calidad en software o exportación de software. ${ }^{30}$ Mediante este bono es posible cancelar impuestos nacionales que tengan su origen en la industria del software ${ }^{31}$.

- La desgravación del 60\% del impuesto a las ganancias (beneficio sujeto a evaluación de la autoridad de aplicación).

- Eliminación de las restricciones al giro de divisas para importación de productos informáticos destinados a la producción de software.

${ }^{29}$ Se trata de la Ley 26.692 que, en el 2011, extendió la vigencia del régimen hasta el 2019, y del Decreto 1201/2018, por el cual se fijó una retención del $12 \%$ a la exportación de servicios desde el 1 de enero de 2019 hasta el 31 de diciembre de 2020, lo cual afectó parcialmente a los productores de software.

${ }^{30}$ Detalles que brinda el decreto reglamentario 1594/2004: "Se entiende que se desarrolla actividad de investigación y desarrollo de software cuando los gastos aplicados a la misma superen el $3 \%$ del gasto total de las actividades sujetas a promoción (...) Dichos gastos serán considerados cuando exista una relación directa entre la actividad de investigación y el desarrollo de nuevos productos (o dispositivos), así como nuevos procesos o servicios, y deben constituir un proyecto específicamente dirigido a elevar el nivel tecnológico de una o más empresas. Las actividades pueden ser ejecutadas en su totalidad por los propios beneficiarios, o bien en colaboración con universidades o institutos de ciencia y tecnología públicos o privados" (art. $8^{\circ}$, inc. A).

${ }^{31}$ Entre ellos, el IVA. No se permite cancelar el impuesto a las ganancias ni deudas contraídas con anterioridad al ingreso al Régimen. 
- Preferencia en la adjudicación de financiamiento proveniente del Fonsoft para las empresas inscriptas en el régimen.

- El Fondo Fiduciario de Promoción de la Industria del Software (Fonsoft) se creó en el marco de la antedicha ley, en el ámbito de la Agencia Nacional de Promoción Científica y Tecnológica (ANPCYT), con el objeto de financiar actividades de innovación de distinto tipo en las firmas de software. Este fondo contempla cuatro instrumentos de financiación: a) aportes no reembolsables (ANR), es decir, subsidios destinados a certificación de calidad, desarrollo de nuevos productos y procesos, I+D precompetitiva; b) emprendedores Fonsoft, es decir, subsidios para financiar proyectos que den origen a nuevas empresas y/o consoliden las existentes con alto grado de innovación; c) créditos exporta, esto es, financian hasta el $80 \%$ del costo total de proyectos de un año de duración, a tasas mínimas y con dos años de gracia, destinados a las actividades empresariales vinculadas con la exportación; d) ANR Fonsoft Capacitación, subsidian a instituciones públicas con aporte fiscal directo o instituciones privadas sin fines de lucro.

De esta manera, como puede observarse, la batería de incentivos que contempla la ley y sus derivados abarca una importante variedad de aspectos en los que las pymes del sector, a las que van dirigidos los distintos incentivos, suelen presentar dificultades.

Transcurridos algunos años de implementación de la ley es posible constatar un crecimiento notable del sector de SSI en una variedad de indicadores, curva que da la pauta de la concurrencia entre la implementación de las políticas y un nuevo comportamiento del sector productivo en cuestión en el periodo analizado ${ }^{32}$.

En la década de los setenta del siglo XX Argentina ya contaba con una oferta local de software, aunque muy limitada ${ }^{33}$. A mediados de los ochen-

${ }^{32}$ Aquí solo haremos referencia a los indicadores sectoriales principales y más significativos para nuestros fines.

${ }^{33}$ Para la descripción del sector informático en Argentina hasta el 2001, nos basamos en el trabajo de Chudnovsky, López y Melitsko (2001). 
ta, el mercado había cuadruplicado su nivel de facturación, aunque en otros indicadores no se habían producido avances de importancia: el $70 \%$ del mercado nacional era abastecido por productos extranjeros, el grado de concentración de la industria era muy elevado, las exportaciones eran ocasionales y los desarrollos se vinculaban casi exclusivamente a aplicaciones administrativas a medida de complejidad menor. Hacia fines de la década de los noventa, el sector facturaba unos 190 millones de dólares y empleaba en total a unas 4500 personas, ${ }^{34}$ pero no presentaba un crecimiento considerable en términos de cantidad de firmas activas, expansión del mercado de desarrollo y niveles de exportación.

En el 2000 se observaron niveles de facturación moderadamente superiores a los mencionados para las décadas anteriores, junto con un leve descenso de la participación de las firmas extranjeras sobre el total facturado y una ampliación del $4 \%$ en la porción de ventas generadas por las empresas nacionales. El empleo tuvo una baja de 1000 puestos con respecto a la década de los noventa entre las firmas locales que, no obstante, mantuvieron un nivel de participación mayor al de las transnacionales en la generación de trabajo en el sector ${ }^{35}$. En cuanto a las exportaciones, las empresas extranjeras lideraban con claridad la actividad con el $73 \%$ del total.

Hacia el 2001, con base en estos indicadores, se estimaba que el sector tenía una importancia significativa en la industria nacional, y que continuaría expandiéndose en términos cuantitativos si se consolidaban dos tendencias observadas durante los últimos años de la década anterior: una mayor disponibilidad de recursos humanos calificados y el avance en la calidad de las telecomunicaciones del país. En la década de los noventa el régimen de convertibilidad cambiaria incentivó la importación masiva de equipamiento informático para el sector de telecomunicaciones. Esto generó una demanda mayor de software y servicios, a partir de la cual la incipiente industria informática experimentó un crecimiento moderado

${ }^{34}$ El salto en el empleo se produjo particularmente en el área de desarrollo de software, que pasó de 1180 empleados, aproximadamente, en la década de los ochenta, a unos 3000 en la de los noventa. El área de servicios informáticos, en cambio, experimentó un descenso durante el mismo periodo, al pasar de 2000 a 1500 personas.

${ }^{35} \mathrm{El}$ cual fue también bastante elevado (42\%, con 2792 personas). 
durante algunos años, basado en actividades de baja complejidad tecnológica (p. ej., venta de licencias y servicios de soporte) realizadas por profesionales especializados cuyo número también aumentó modesta pero significativamente en comparación con las décadas anteriores (Aspiazu, Basualdo y Nochteff, 1986; 1990).

La década de los noventa estuvo signada por la ausencia de políticas específicas y sistemáticas para la promoción de la industria del software (Yoguel, Lugones y Stulzwark, 2007). El instrumento que más se aproximó a una política de incentivo fue el Fondo Tecnológico Argentino (Fontar), creado en 1995 con el objetivo de financiar, a través de fondos internacionales, los proyectos de modernización tecnológica de pymes industriales e instituciones públicas de ciencia y tecnología. Los fondos no eran direccionados a sectores específicos y las empresas beneficiadas eran mayoritariamente manufactureras ${ }^{36}$. A su vez, en comparación con países vecinos como, por ejemplo, Brasil y Uruguay, la carga impositiva que enfrentaban las empresas del sector informático en Argentina era relativamente alta y no existían incentivos a la radicación de empresas extranjeras para producir software en el país.

La ausencia de políticas sectoriales estaba asociada a la falta de reconocimiento por parte del Estado argentino del carácter estratégico del sector de SSI, a diferencia de lo ocurrido en otros países de nuestro continente ${ }^{37}$.

${ }^{36}$ Entre 1995 y el 2001 el Fontar aprobó un total de 778 proyectos correspondientes a 850 empresas entre sus diferentes líneas de apoyo financiero, prevaleciendo el acceso a crédito fiscal y a consejerías tecnológicas dedicadas a la asistencia técnica (Yoguel et al., 2007).

${ }^{37}$ En Brasil, por ejemplo, existían numerosos programas dirigidos al sector, omo DESI-BR (Desarrollo Estratégico en Informática en Brasil), Softex (Sociedad para la Promoción de la Excelencia del Software Brasileño), PD\&I-TI (Programa de Apoyo a la Investigación, Desarrollo e Innovación en Tecnologías de la Información), Brains de Brasilia (Brazilian Intelligence in Software), Programa Finansosft a cargo del Banco de Desarrollo o BNDES (catálogo de fuentes de financiamiento y de capital de riesgo para empresas de software), o el Proyecto Petrópolis-Tecnópolis (polo de actividades tecnológicas), entre otros. En Uruguay existía, por ejemplo, el "Programa de Desarrollo Empresarial de la Industria del Software" (BID/Fomin), programas para nuevos negocios en el sector de las TIC, Agenda INFO-Uruguay 2000/Polo Tecnológico Software -Uruguay/Tecnosis, y Zona Franca Montevideo (exención impositiva total), entre otros (Uriona, Morero y Borrastero, 2013). 
En síntesis, la necesidad de impulsar el desarrollo del sector de SSI a nivel local no formaba parte de la agenda pública y no existía una estrategia nacional dirigida a este objetivo.

Durante el periodo de transición 2001-2002, pese a la abrupta salida del régimen monetario vigente y a la profundidad de la crisis, las tendencias de largo plazo observadas para el sector informático durante la década anterior persistieron, en el marco del crecimiento del sector de SSI a nivel global. Al mismo tiempo, el tipo de cambio alto favorable a la exportación y la competitividad-salario se mantuvo durante el nuevo gobierno del presidente Néstor Kirchner y constituyó una oportunidad macroeconómica diferencial para impulsar el crecimiento de esta industria.

En el periodo 2003-2005, que contiene la formulación e inicial implementación de la política bajo análisis, "actividades informáticas” fue la segunda rama de la economía en términos de creación de empresas con una tasa del 20,6\%, casi duplicando la tasa promedio de la economía, con un $13,6 \%$ para el total de sectores de la industria, comercio y servicios (Castillo, Rivas, Rojo y Rotondo, 2006).

La Tabla 2 muestra de forma sintética lo acontecido con el empleo, la cantidad de empresas, las ventas y las exportaciones del sector durante toda la década posterior a la sanción de la ley.

Tabla 2. Principales indicadores del sector de software argentino (2003-2015)

\begin{tabular}{ccccc}
\hline & Empleo & Cantidad de & Ventas & Exportaciones \\
\cline { 5 - 5 } Año & (miles de puestos) & empresas & $\begin{array}{c}\text { (millones } \\
\text { de USD) }\end{array}$ & (millones de USD) \\
\hline 2003 & 19,3 & 1852 & 916 & 170 \\
\hline 2004 & 26,3 & 2288 & 1119 & 220 \\
\hline 2005 & 32,9 & 2681 & 1279 & 247 \\
\hline 2006 & 40 & 3034 & 1504 & 300 \\
\hline 2007 & 45,7 & 3381 & 1776 & 387 \\
\hline 2008 & 52,9 & 3602 & 2333 & 504 \\
\hline
\end{tabular}




\begin{tabular}{ccccc}
\hline & Empleo & Cantidad de & Ventas & Exportaciones \\
\cline { 5 - 5 } Año & (miles de puestos) & empresas & $\begin{array}{c}\text { (millones } \\
\text { de USD) }\end{array}$ & (millones de USD) \\
\hline 2009 & 55,9 & 3714 & 2226 & 547 \\
\hline 2010 & 60,1 & 3905 & 2642 & 663 \\
\hline 2011 & 64,3 & 4087 & 3063 & 792 \\
\hline 2012 & 69,5 & 4226 & 3388 & 926 \\
\hline 2013 & 73,5 & 4288 & 3447 & 896 \\
\hline 2014 & 77,4 & & 3067 & 1004 \\
\hline 2015 & 81,8 & & 3479 & $2016)$. \\
\hline
\end{tabular}

Fuente: Motta, Morero y Borrastero (2017) con base en OPSSI (2015; 2016).

Como puede apreciarse en la tabla 2, el número de empresas activas se duplicó, creciendo a un ritmo del 9\% anual hasta el 2013. Además, se estima que en el 2010 existían unas 2400 microempresas (Barletta, Pereira, Robert y Yoguel, 2012) que no son contabilizadas en el total. Otro aspecto saliente de la etapa, en particular entre el 2007 y el 2011, es la alta presencia de pymes, lo cual manifiesta una densificación de este subsegmento de la industria (Borrastero, 2015). A lo largo del periodo el sector mantiene un coeficiente exportador de entre el $25 \%$ y $30 \%$ de las ventas (Motta et al., 2017). En materia de empleo, la dinámica sectorial es más notable aún: la cantidad de ocupados del sector creció de manera ininterrumpida durante la posconvertibilidad, desde un nivel de 19000 ocupados en el 2003 a más de 77000 en el 2014, a una tasa promedio anual cercana al $14 \%$ (con tasas promedio anuales del 22,6\% hasta el 2008 y llegando a crecer más del $36 \%$ en el 2004 , pero considerando también los años en que el empleo creció a tasas de entre el $5 \%$ y el $8 \%$ ) (Motta et al., 2017). El volumen de ventas del mercado de software argentino prácticamente se cuadriplicó para el 2004 con respecto a sus niveles de fines de la década de los noventa, y era dieciocho veces más grande en el 2013, aunque había caído en el 2009 luego de la crisis mundial (con todo, la tasa de crecimiento anual de las ventas del sector fue del $12 \%$, entre el 2003 y el 2014) (Motta et al., 2017). 


\section{DISCUSIÓN DE LOS RESULTADOS DEL ANÁLISIS EMPÍRICO Y CONCLUSIONES}

En relación con las intervenciones sectoriales del Estado nacional, durante el periodo analizado es posible distinguir dos etapas: la primera marcada por intervenciones político-institucionales y la segunda por intervenciones predominantemente económicas.

La primera etapa se inicia en el 2000, en la que predominan intervenciones político-institucionales orientadas a articular a los actores de la industria representados en las entidades empresarias que participaron de manera activa en la definición de la política sectorial en aquel periodo, a partir del reconocimiento de algunas de sus demandas históricas más importantes.

Dichas demandas son impulsadas principalmente, acciones empresarias de entidades corporativas del sector, inicialmente asentadas en tres de las prácticas que Tirado considera vías de acceso de los empresarios al Estado: a) acudir al Gobierno y al parlamento para plantear sus demandas; b) actuar al interior de sus organizaciones representativas, de modo que se logre un proceso de agregación de intereses exitoso intra e intercámaras (por parte de las empresas particularmente interesadas en el proceso de articulación); c) comparecer de manera recurrente ante la opinión pública a través de medios de comunicación masiva a fin de presentar y defender sus intereses (esto como estrategia habitual de generalización de dichos intereses y estrategia de mediación orientada específicamente al Estado) ${ }^{38}$.

A partir de la instalación efectiva de las demandas, en el proceso se generan articulaciones público-privadas basadas, centralmente, en prácticas de colaboración, prácticas institucionalizadas de vinculación (principal-

${ }^{38}$ Según las fuentes consultadas en la investigación, las empresas no recurrieron a vínculos con partidos políticos como recurso predominante de acercamiento a los espacios estatales de definición de la política sectorial. 
mente, los foros de competitividad) y prácticas de influencia directa sobre los espacios estatales ${ }^{39}$.

La segunda etapa que identificamos se abre en el 2003 a partir del decreto que declaraba la producción de software como industria. Allí predominan las intervenciones económicas del Estado, orientadas a fortalecer las pymes, principalmente, a través de subsidios y créditos de acceso directo (es decir, instrumentos no mediados por las entidades corporativas). Las intervenciones político-institucionales surgidas en la etapa anterior continúan su curso en el marco de los espacios en funcionamiento.

Ambos tipos de intervención estatal -económica y político-institucional- se enmarcan en la estrategia económica general observada para el Estado argentino en este periodo de crisis, tendiente, primero, a la creación de empleo, y luego a un desarrollo de la industria nacional basado en el fortalecimiento de sectores productivos con ventajas disponibles en el ámbito de los servicios. Dicha estrategia se comprende, a su vez, en el contexto de ciertos factores sectoriales precipitantes de la elección del sector de SSI como industria a promover, específicamente: a) la situación de Argentina como economía en crisis, pero que contaba con recursos humanos formados para el trabajo intelectual y el desarrollo de bienes y servicios intangibles en virtud de su sistema y su tradición de educación superior de amplio acceso; b) Argentina como Estado que buscaba crecer de modo acelerado y sostenido insertándose en la economía internacional como proveedora de servicios informáticos, a la par de las actividades económicas tradicionalmente desarrolladas en el país (Ministerio de Economía y Producción de la Nación Argentina, 2004).

En este sentido, observamos, en primera instancia, que el Estado muestra capacidad para aprovechar las oportunidades que ofrece una coyuntura económica general actualmente negativa, en favor del crecimiento de la industria de SSI con base en la devaluación monetaria. Esto es, las limitaciones estructurales para el logro de esta finalidad, impuestas por la profunda cri-

${ }^{39}$ En el relevamiento de fuentes acerca de este asunto no detectamos referencias a prácticas de colonización de espacios de la administración pública, prácticas colusorias o prácticas de corrupción. 
sis económica y política que afectaba particularmente a la industria ${ }^{40}$, y las vulnerabilidades propias de un Estado reducido a su mínima expresión y un poder político deslegitimado por la sociedad, se transforman en oportunidades a partir del despliegue de una estrategia concebida en el marco de un cambio del horizonte cognitivo de posibilidades de los actores políticos que detentan el poder del Estado. En dicho horizonte ingresan como factor novedoso las potencialidades de inserción internacional de Argentina en la "economía del conocimiento", basadas en el desarrollo de las ventajas comparativas que ya señalamos. En esta dirección operan con claridad los imaginarios económicos constituidos y en expansión de los actores protagonistas, vinculados a las nuevas cadenas globales de valor más pujantes en el ámbito de los servicios en aquellos años.

Este conjunto de cambios implica una ruptura en el sendero evolutivo que venían transitando las intervenciones estatales en el sector productivo en su conjunto, en el marco del régimen de convertibilidad cambiaria (marcadamente favorables a las importaciones y a la concentración de los mercados) y, al mismo tiempo, un tipo de "efecto demostración" respecto a la necesidad de incidir a través de políticas específicas del Estado en el sector en cuestión, considerando que la mera existencia de oportunidades globales o macroeconómicas a nivel nacional no necesariamente redunda en beneficios sectoriales si no son mediadas por políticas ad hoc (Aspiazu et al.,1986; 1990).

A lo largo de todo el proceso de articulación entre los empresarios y el Estado en este periodo es posible constatar tanto el despliegue de intervenciones estatales de calidad como de acciones empresarias que otorgan un lugar de relevancia a la articulación y sus emergentes.

Respecto a las dimensiones interna y externa de las intervenciones estatales, observamos que el Estado es capaz oportunamente de mostrar un

${ }^{40}$ No así a otros sectores de la economía — como, por ejemplo, el sector financiero y los grandes importadores de bienes de consumo, quienes se vieron beneficiados por las políticas de libre cambio instaladas a partir de la última dictadura militar y profundizadas durante la década de los noventa bajo los gobiernos de Carlos Menem y Fernando De la Rúa. 
desempeño consistente con las necesidades y las estrategias planteadas, en ambas dimensiones.

En relación con la dimensión interna, advertimos:

- La generación de un desarrollo de las capacidades administrativas de las agencias estatales involucradas que permitió la convergencia necesaria a los fines de efectivizar las políticas diseñadas, en el marco de una finalidad común y una racionalidad estratégicamente orientada al crecimiento del sector (Secretaría de Industria, Secretaría de la Pequeña y Mediana Empresa [INTI], principalmente).

- La disposición, por parte del Estado, de los recursos financieros, organizacionales y técnicos requeridos para el desarrollo de las distintas acciones de promoción que financien la realización de las instancias de articulación e inyecten fondos en las empresas a partir de financiamiento específico del Banco Interamericano de Desarrollo.

En relación con la dimensión externa de las intervenciones estatales, es posible observar:

- Que es alto el grado de connivencia alcanzado entre el Estado y los empresarios en función de la estrategia de crecimiento sectorial definida de manera conjunta, aun en el marco de dos condicionamientos que en principio no garantizaban una articulación virtuosa. Por una parte, la inexperiencia o experiencia negativa previa de los actores involucrados en la promoción del sector, dado el conjunto de novedades políticas y económicas propias de la coyuntura que describimos más arriba. Por otra, la situación de convulsión política y económica generalizada que caracterizó el periodo de salida de la convertibilidad, en particular: 1) la inestabilidad de un gobierno con una legitimidad política muy reducida y un apoyo internacional hasta ese momento indefinido; y 2) la profundización de la disputa por los recursos del Estado por parte de todos los sectores económicos, propia de las situaciones de crisis general. La connivencia Estado-empresarios, en el contexto que describimos, da cuenta de la generación de una activa dinámica autonomía-enraizamiento, asentada sobre un tipo de enraizamiento en el sector productivo que, si bien no existía previamente a este grado, tuvo lugar con rapidez en 
virtud de la asunción por parte del Estado de las demandas empresariales desestimadas en la historia reciente de la industria.

- Por último, observamos que no son necesarias intervenciones estatales dirigidas al disciplinamiento de los sectores empresarios involucrados, dada la impronta colaborativa del proceso de articulación y el carácter incipiente de las políticas sectoriales diseñadas. En este punto cabe aclarar que la captación del grado de reciprocidad alcanzado en la articulación es posible para este periodo inicial solo al nivel de las intervenciones político-institucionales (no así al nivel de las intervenciones económicas).

Con respecto a la acción empresaria en el sector, constatamos que durante el periodo de análisis se encuentra también orientada, sobre todo, al establecimiento de arreglos institucionales en articulación con el Estado que dan lugar a una participación activa y regular del empresariado en la definición de la política sectorial. El empresariado pyme corresponde de forma oportuna a los esfuerzos estatales realizados en materia de relevamiento de la situación del sector. De forma paralela, si bien el proceso de articulación es finalmente exitoso, es necesario remarcar que el empresariado local sostuvo sus demandas no respondidas durante un tiempo ${ }^{41} \mathrm{y}$, en este sentido, se mostró muy activo en la disputa por los recursos del Estado ante otros actores empresarios que también pugnaban por ellos. Esto, incluso, desde tiempos anteriores a la existencia de una política pública sistemática, ganando terreno en este aspecto e incidiendo a su vez, sobre la intervención estatal en el sector.

En relación con la acción económica empresaria, dado el tamaño relativamente reducido de la población de empresas en aquellos años y la corta edad de las firmas que surgieron al calor de los acontecimientos que relatamos, no es posible para este periodo captar con precisión las acciones microeconómicas del empresariado. No obstante, a partir de los indicadores agregados del crecimiento sectorial que presentamos y las evaluaciones cualitativas del empresariado con respecto a las intervenciones estatales implementadas a partir de sus propias demandas — captadas

${ }^{41}$ Principalmente la relacionada con la indistinción entre PyMEs y grandes empresas en el Régimen de Promoción. 
por medio de entrevistas ${ }^{42} \mathrm{y}$ análisis documental — es posible afirmar que el impacto de las intervenciones es positivo en términos generalizados, sobre todo en relación con la situación anterior de ausencia de políticas.

Un último elemento que sobresale en el análisis y contribuye a sustentar algunas de las afirmaciones anteriores es el hecho de que una parte importante de las políticas demandadas y finalmente implementadas se dirige a apoyar de manera específica la innovación en el sector, principalmente en el caso de tres de los instrumentos creados: el bono fiscal que permite a las empresas descargar hasta el $70 \%$ de las contribuciones patronales en impuestos cuando realizan actividades innovadoras o exportación de software; y los subsidios de las líneas ANR y de emprendedores Fonsoft que financian proyectos de innovación. Al considerar que la financiación de los costos de innovación es uno de los objetivos centrales tanto de las empresas de este sector en sus demandas como del Estado en su atención, podemos afirmar que en este caso ni las intervenciones estatales ni la acción empresaria buscan, de manera predominante, la generación de rentas de privilegio en el sector, sino crear mejores condiciones de posibilidad para la generación de rentas tecnológicas.

En el conjunto del periodo analizado se observa entonces una modelación recíproca de las acciones del Estado y los empresarios, dirigidas al crecimiento del sector. Las articulaciones público-privadas permiten generar aprendizajes institucionales de carácter interactivo en virtud del componente estratégico que caracteriza la acción de ambos actores. De esta manera, es posible construir e implementar una política pública efectiva y sostenible en el tiempo que coadyuve, entre otros factores, a un salto en el desempeño sectorial y, consecuentemente, a su presencia en la estructura

${ }^{42}$ Se listan aquí las entrevistas realizadas utilizando el nombre de las empresas y no de los informantes clave consultados por requerimientos de confidencialidad (CEO o gerentes de diversas áreas) y sin consignar una referencia específica del entrevistador por requerimientos de anonimato, ya que se ha tratado en todos los casos del autor del presente artículo: Motorola, Córdoba, 26/7/2013; Intel, Córdoba, 14/8/2013 y 23/8/2013; Acriter (CABA), vía Skype, 22/4/2016; Core (CABA), vía Skype, 12/5/2016; Technisys (CABA), vía Skype, 3/10/2016; Kinexo (Rafaela), vía Skype, 22/5/2017; E-ducativa (Rosario), vía Skype, 4/7/2017; Tecso (Rosario), vía Skype, 1/8/2017; Vates (Córdoba), vía Skype, 7/7/2014; Machinalis, Córdoba, 18/10/2013. 
económica del país, con lo cual contribuya activamente a su consolidación como un nuevo y relevante sector industrial en Argentina.

En suma, los hallazgos del estudio empírico permiten afirmar que el accionar y las relaciones del Estado y los empresarios, en virtud de los altos grados de enraizamiento y reciprocidad alcanzados, resultan decisivos en el caso de estudio como factores precipitantes de la dinámica y la intensidad específicas del proceso de desarrollo sectorial, a partir del modo en que surgió y se instaló la necesidad del crecimiento sectorial como cuestión relevante en el marco de los imaginarios económicos circulantes.

No obstante, y como es de suponer, los factores explicativos del crecimiento sectorial abordados en nuestro análisis no son los únicos posibles. Queda entonces para futuros trabajos el abordaje específico de los determinantes globales del proceso de desarrollo sectorial junto a aquellos macro y microeconómicos propios del contexto local potencialmente relevantes para comprender el impacto de la política.

\section{REFERENCIAS}

Amsden, A. (1992). Asia's next giant South Korea and late industrialization. Oxford, EE. UU.: Oxford University Press.

Aspiazu, D., Basualdo, E. y Nochteff, H. (1986). Estructura y transformaciones de la industria electrónica en Argentina (Documentos e Informes de Investigación, N. ${ }^{4}$ 5, área Tecnología y Sociedad). Argentina: Flacso.

Aspiazu, D., Basualdo, E. y Nochteff, H. (1990). Política industrial y desarrollo reciente de la informática en la Argentina (Documento de Trabajo 34). Buenos Aires: Cepal.

Barletta, F., Pereira, M., Robert, V. y Yoguel, G. (2012). Capacidades, vinculaciones, y performance económica. La dinámica reciente del sector de software y servicios informáticos argentino. Ponencia presentada en la la 41 JAIIO, relaizada en La Plata.

Bekerman, M. y Cataife, G. (2001). El sector software en Argentina: situación actual y sugerencias de políticas (Documentos de Trabajo del Cenes). Facultad de Ciencias Económicas, Universidad de Buenos Aires.

Beltrán, G. (2012). Las prácticas del poder. Discusiones en torno al problema de la acción política empresaria. Apuntes, $\operatorname{XXXIX(70),~69-101.~}$ 
Borrastero, C. (2011). Intervención estatal, transformaciones en los vínculos con el sector privado y crecimiento económico sectorial. El caso del sector de software y servicios informáticos de la ciudad de Córdoba. 2000-2010. Hindustria, 5(8), 1-35.

Borrastero, C. y Castellani, A. (2018). Estado y empresarios en la configuración de ámbitos estratégicos de acumulación: el caso del sector software Córdoba, Argentina (2000-2013). Estado y Políticas Públicas, VI(X), 171-193.

Castellani, A. (2006). Estado, empresas y empresarios. La relación entre intervención económica estatal, difusión de ámbitos privilegiados de acumulación y desempeño de las grandes firmas privadas. Argentina 1966-1989 (Tesis de doctorado). Facultad de Ciencias Sociales, Buenos Aires, Aregntina, UBA.

Castellani, A. (2010). Privileged accumulation spaces and restrictions on development. State-Business relation in Argentina (1966-1989). American Journal of Economics and Sociology (en prensa).

Castellani, A. y Borrastero, C. (2013). Estado y empresarios en el desarrollo de industrias estratégicas: la configuración del sector de software y servicios informáticos de la ciudad de Córdoba (2000-2010). En M. Rougier (comp.), Estudios sobre la industria argentina 3 (pp. 311-345), Buenos Aires: Ed. Lenguaje Claro.

Castellani, A. y Llanpart, F. (2012). Debates en torno a la calidad de la intervención estatal. Papeles de Trabajo, 6(9), 155-177.

Castellani, A. y Serrani, E. (2010). La persistencia de los ámbitos privilegiados de acumulación en la economía argentina. El caso del mercado de hidrocarburos entre 1977 y 1999. Revista H-industri@, 4(6).

Castillo, V., Rivas, D., Rojo, S. y Rotondo, S. (2006). La creación de nuevas empresas durante la etapa post-convertibilidad (2003-2005): impacto sobre el empleo asalariado registrado (Serie Estudios del Ministerio de Trabajo, Empleo y Seguridad Social, N. ${ }^{\circ}$ ). Buenos Aires.

Chibber, V. (2003). Locked in place. State-building and late industrialization in India. Princeton: Princeton University Press.

Chudnovsky, D., López, A. y Melitsko, S. (2001). El sector de software y servicios informáticos (SSI) en la Argentina: Situación actual y perspectivas de desarrollo (Documentos de Trabajo del Cenit, N. $\left.{ }^{\circ} 27\right)$. Buenos Aires.

Denzin, N. K. y Lincoln, Y. S. (Eds.) (2005). The SAGE handbook of qualitative research. Sage.

Dossi, M. y Lissin, L. (2010). La acción corporativa: propuesta de abordaje para el estudio del empresariado. Ponencia presentada en las V Jornadas de Estudios Sociales de la Economía, Idaes-Unsam, realizadas en Buenos Aires. 
Evans, P. (1995). Embedded autonomy. States and industrial transformation. Princeton: Princeton University Press.

Evans, P. (1996). El Estado como problema y como solución. Desarrollo Económico, 35(140), 529-562.

Gajst, N. (2011). Las políticas públicas dirigidas a la industria del software y servicios informáticos de argentina en la posconvertibilidad: una historia de la cuestión. En IX Jornadas de Sociología de la UBA, Buenos Aires.

Gutman, V., López, A. y Ubfal, D. (2006). Un nuevo enfoque para el diseño de políticas públicas: los foros de competitividad (Documentos de Trabajo del Cenit, N. ${ }^{29)}$. Buenos Aires.

Heredia, B. (1996). State-Business relations in contemporary México. En M. Serrano y V. Bulmer-Thomas (Eds.), Rebuilding the State: México after Salinas. Londres: The Institute of Latin American Studies, University of London.

Hyoung Ji, J. y Kytir, S. (2014). The strategic-relational approach: an interview with Bob Jessop. Recuperado de http://bobjessop.org/2014/12/02/the-strategicrelational-approach-an-interview-with-bob-jessop/.

Jessop, B. (1990). State theory: putting capitalist states in their place. RU: Penn State University Press.

Jessop, B. (2007). State power: a strategic-relational approach. RU: Polity Press.

Jessop, B. (2009). Cultural political economy and critical policy studies. Critical Policy Studies, 3,3, 336-356.

Jessop, B. (2014). El Estado y el poder. Utopía y praxis latinoamericana, 19(66), $19-35$.

López, A. (2002). El sector de software y servicios informáticos en la Argentina: ¿es posible una inserción exportadora sostenible? Ponencia presentada en el Seminario Internacional Redes, TIC y Desarrollo de Políticas Públicas. Universidad Nacional de General Sarmiento, Buenos Aires.

MacIver, R. M. (1949). Causación social. México, D.F.: Fondo de Cultura Económica.

MacIver, R. (1968). El papel del precipitante. En A. Etzioni (Ed.), Los cambios sociales (p. 377), México: Siglo XXI.

Ministerio de Economía y Producción de la Nación Argentina-Secretaría de Industria, Comercio y de la Pequeña y Mediana Empresa (2004). Plan Estratégico de SSI 2004-2014/Plan de Acción 2004-2007 (Documento resultado del Foro de Competitividad de Software y Servicios Informáticos).

Motta, J., Morero, H. y Borrastero, C. (2017). La industria del software: la generación de capacidades tecnológicas y el desafío de elevar la productividad sistémica. En M. Abeles, M. Cimoli y P. Lavarello (eds.), Manufactura y 
cambio estructural. Aportes para pensar la politica industrial en la Argentina (pp. 283-330). Buenos Aires: Cepal.

Ozslak, O. y O’Donnell, G. (1976). Estado y políticas estatales en América Latina: hacia una estrategia de investigación (Documento Clacso-Cedes N. ${ }^{\circ}$ ). Buenos Aires.

Rebossio, A. (10 de julio de 2003). El software espera la ley de promoción. La Nación. Recuperado de https://www.lanacion.com.ar/economia/el-softwareespera-la-ley-de-promocion-nid510278

Rougier, M. (2011). Estado y empresarios en la industria del aluminio en la Argentina: el caso Aluar. Bernal: Editorial de la UNQui.

Schneider, B. R. (1995). El abrazo esquivo: sinergia entre el sector privado y el Estado en los países de industrialización reciente. Política y gobierno, II(1), 5-41.

Schneider, B. R. y Wolfson, L. (1999). Las relaciones entre el Estado y las empresas y sus consecuencias para el desarrollo: una revisión de la literatura reciente. Desarrollo Económico, 39(153), 45-75.

Sin autor (20 de junio de 2002). Se mudan a Uruguay por falta de incentivos. La Nación. Recuperado de https://www.lanacion.com.ar/economia/se-mudana-uruguay-por-falta-de-incentivos-nid406726

Sin autor (20 de junio de 2002). Los polos tecnológicos buscan exportar. La Nación. Recuperado de https://www.lanacion.com.ar/economia/los-polostecnologicos-buscan-exportar-nid 406725

Sin autor (17 de julio de 2003). Reclamo de la industria informática. La Nación. Recuperado de https://www.lanacion.com.ar/

Sin autor (3 de diciembre de 2003). Media sanción al proyecto de promoción de la industria del software. La Nación. Recuperado de https://www.lanacion. com.ar/

Tirado, R. (2006). El poder en las cámaras industriales de México. Revista Foro Internacional, XLVI(184), 197-226.

Uriona, M., Morero, H. y Borrastero, C. (2013). 'Catching up' en servicios intensivos en conocimiento: el caso de la producción de software y servicios informáticos de Argentina y Brasil. Revista Iberoamericana de Ciencia, Tecnología y Sociedad, 8(24), 117-146.

Viguera, A. (1998). Estado, empresarios y reformas económicas: en busca de una perspectiva analítica integradora. Perfiles Latinoamericanos, 12.

Yoguel, G., Lugones, M. y Stulzwark, S. (2007). La política científica y tecnológica argentina en las últimas décadas: algunas consideraciones desde la perspectiva del desarrollo de procesos de aprendizaje. Santiago de Chile: Cepal. 